\title{
ETHNO-SEASONALITY AND THE SOCIAL LIFE AMONG THE HIGHLANDERS
}

\author{
Jiban Mani Poudel ${ }^{1}$
}

\begin{abstract}
This paper is about how the seasons and social life of the highlanders are interconnected to each other. It largely concerns on two thematic areas: documentation of emic perspective of naming systems of seasons, and accounting the interconnectedness of seasons and social life of highlanders who live in Nhāson, a small mountain valley located in the central Himalayan region of Nepal. Information is based on 9 months place-specific ethnography in different periods from the years 2012 to 2018 . Informal conversation with the local people and observation of the physical environment and socio-cultural life were the key sources of understanding the interconnectedness of seasons and social life of the highlanders. Findings show seasons are the parts of social life for the highlanders. The change of seasons from one season to another is not just a matter of change in weather patterns and the associated changes in physical environment of the surrounding but it is also a change in social life. Therefore, physical and social seasonality go side by side as rhythms which are the integral parts of culture and social life of highlanders. Moreover, local's definition of seasons is cultural specific and place-specific that challenges state defined universal definition of seasons and force to rethink it differently.
\end{abstract}

Keywords: Ethno-seasonality, Social life, Human-nature Relationship, Highlanders

\section{INTRODUCTION}

Anecdotes that I heard in two different seasons from my informants were really struck my mind to see how seasons are understood by local people in their cultural context and how social life are interconnected with seasons. At the end of September 2012, I was at Wagreche pastureland (3,700 meters), one of the high pasturelands of Nache village. One day, I

1 Dr. Poudel is a Lecturer, Central Department of Anthropology, Kathmandu TU. 
was talking with herders about the availability of ground grasses for their livestock. Ganjaman, the eldest herder said, 'Norusaiba almost begins at Wagreche'. I did not understand him, and then asked to him about it. He described it like this:

Look at! The blow of cold wind and dewfall begins here. Along with it, the ground-grasses on meadows gradually will go to brown, and finally die. Leaves on trees will start to fall. It is called norusaiba. It varies by altitudes. It starts earlier in high altitude, and later in low altitude. With the beginning of norusaiba, herders also start to move their herds to downward to protect them from cold. (Ganjaman Gurung 63 years old).

On the $2^{\text {nd }}$ week of May 2013, I was doing kurakani (informal conversation) on local naming systems of seasons and the changes with some elderly people sitting on a big rounded-stone located at the center of Nache village. By pointing at the forests around the village, one elderly man remarked;

Look at the village and its surroundings (approximately 2,1002,500 meters)! Everything is written there. Here, rhododendron flowers have been already withered and almost fallen down. Now, it is blooming at Kromche and the surroundings (about 3,000 meters). You know flowering of rhododendron tells us about the availability of ground grasses. Now, you can see ground grasses at Kromche. Very soon, village's herds will be there for grazing. (Somlal Gurung, 52 years old)

The narratives are telling the physical seasonality (onset of dewfall, decline of ground grasses, blooming and wrinkling of rhododendron) and socio-cultural seasonality (movement of herds and customary law) are not treated as separate entity by the herders who live in Nhāson valley of Manang. They go together as rhythms. The beginning of narusaiba and flowering of rhododendron may be natural events for outsiders, but the herders of Nhāson they are more than that. The first anecdote telling to be ready to herders for downward mobility of livestock due to lack of ground grasses on pasturelands. On the contrary, the latter anecdote is notifying time for the upward mobility of livestock with the place for grazing to the herders. Such pragmatic knowledge embedded with land or environment (Basso, 1996, Ingold, 2000, Ingold and Kurtilla, 2001, Berkes, 2008). It might inform us about human adaptation to seasons/environment that has 
been generated by the local people through the observation of the local markers for ages what is called indigenous knowledge.

Anthropologists have been doing research in Nepal since the mid 1950s. Since then, the Himalayan region has remained as a prime location for anthropologists for studies. It may be due to good climate, unique culture and friendly people and now climate change. In the 1970s and early 80 s, human-nature relation was one of the important themes of inquiry for anthropologists in Nepal (von Furer-Haimendorf 1980, Molnar 1981, Fisher 1987) and even today its craze has not been faded out (Bauer 2004; van Spengen 2010, Spoon 2011, Sherpa 2014, Poudel 2016b, 2018a \& 2018b). However, interconnectedness of seasons and seasonality is still in shadow in the context of Nepal. In this context, this paper seeks the answer of the questions - how people name seasons; what seasons are for the highlanders and how seasons and seasonality are interconnected to each other. These are simple but academically very important for inquiry to understand humannature relationship in the mountain region.

\section{ANTHROPOLOGY OF SEASONALITY}

Season, in common, is understood as division of a year into parts based on different weather patterns appear in different periods. It is not simply a division of a year, but it is a socio-cultural phenomenon (EvansPritchard 1940 \& 2004, Mauss 1976, Harris 1998, Orlove 2003, Berkes 2008, Krause 2013 \& Poudel 2016a). Each cultural group has one's own system of naming seasons and their own way of understanding to it what is known as ethno-seasonality. In the review article Orlove (2003) states that a single culture may contain multiple frameworks for marking and counting years. It means there is no 'seasons in general' for a single cultural group. Nhāson, dominated by Gurung culture, they have multiple frameworks for conceptualizing seasons and seasonality largely based on movement of livestock and weather patterns appearance in the surroundings.

Seasons and seasonality are not new subjects for anthropologists. Anthropologists have been studying it from two perspectives i.e. human ecological perspective and ethno-ecological perspective. The first perspective sees it as a process, and the latter one folk taxonomy. Those who see seasons as process, they try to see the relation of human society with seasons (Evans-Pritchard 1940, Mauss 1976, Harris 1998, Ingold \& Kurttila $2001 \&$ Krause 2013). They argue that socio-cultural life moves according to seasons as rhythms. They do not see seasons and socio-cultural life as different entity. For instance, Mauss (1976) writes that the social life of 
Eskimo - forms of family, systems of law, moral codes, domestic economy and religious life - is as opposed forms in winter and summer seasons. In the winter season, social life is stronger and wider religious unity among Eskimos which is not found in the summer. It is sharply isolated and widely fragmented. Similarly, Evans-Pritchard (1940) has described that the Nuer southern Sudan are with their herds that moves from villages to ridges during the tot (rainy) season, and the herds are widely scattered during mai (drought) season. The cases reflect that seasons and seasonality are the two sides of the same coins.

As Mauss and Evans-Pritchard, Mark Harris looks at seasonality which defines as embodied periodicity, produced in the attendance of people to their environment (Harris 1998). This seasonality implies that life on the Amazon varies most radically between a period of economic scarcity, illness and kin aesthetic limitation to people's houses when the river floods the plain, and a period of relative abundance, happiness and village festivals, when river discharges are low. Harris concludes that

the periodicity of social life on the Amazon floodplain is neither due to pressure and necessity, nor to an environmentallyimposed social structure to which individuals conform. Instead, [. . .] for Parúaros the annual rhythm is inherent in the process of social life. Seasonality is intrinsic to people's engagement with, and perceptual alertness to, a changing environment which, in turn, is integrated with the changing constellations of their social relationships (1998, p. 79).

Krause (2013) also argues that season happens in time, but it is not a series of event that can be ordered along a uniform and external temporal trajectory. Instead, season is embodied and enacted, an integral part of the activity practiced or the process performed by the community. Therefore, seasonal variations are not parts of physical variations, but are striking and constitute a central aspect of the Kemi river dwellers' lives. In this way Krause also does not see seasons and lives of Kami river dwellers as distinct phenomena.

The root of second approach is ethno-taxonomies of color, plants, animals, diseases etc. As color, plants, animals and diseases taxonomy, it classifies the seasons based on temporal dimensions. Orlove (2003) has complied twenty-eight cases of local naming of seasons. The approach provides a detail naming systems of seasons, but it largely ignores 
intersection between socio-cultural activities and seasonality in detail. The later approach does not see seasons as part of people's life-world.

By reviewing these approaches, I argue that one approach cannot fully account complexity of human relations with natural world including seasons and seasonality. The nexus of both approaches can help us to understand complex relation between social-cultural life and seasons in holistic way.

\section{STUDY AREA AND METHOD}

Nhāson valley is located in the southeast part of Manang district. Annapurna mountain range is located in the southwest and Manasulu in the northeast of the valley. The altitude of the valley is ranging from 1,645 to 8,125 meters from the sea level (HMG/N 2000). The variations in altitude create wider diversity in weather patterns at a given time of a year. For instance, the spring season comes earlier in the lower altitude and later in the higher altitude. The fall season begins early in the higher altitude and lately to the lower altitude.

In 2018, there were 16 settlements in the valley. Ghale, Gurungs, Lama, Tamang, Thakali, Kami and Damain are inhabitants of the area. Sapri Ghale, one of clans of Ghale, is the earliest settler in the valley (Poudel 2018a). However, Gurungs are numerically the dominant social group. The oral history of the Sapri Ghale tells that human settlement began at the valley in the $11^{\text {th }}$ century. Even today, Sapri Ghale is socio-politically powerful group.

Local economy has been rest on subsistence based agriculture, livestock and trade. Even today, subsistence based agriculture is the dominant way of livelihood, but herding is up and down. To some extent, it has declined. Now, tourism based economy has became the dominant way of living. Today, almost all settlement have involved in tourism hotel business.

This paper was based on ethnographic study carried out in different times between the years 2012 to 2018 . My earlier study was between the year 2012 to 2014 which focused on local knowledge, perceptions and adaptation on climate change. At that time, I collected local naming systems of seasons and observed the socio-cultural life of the people in different seasons. I talked to farmers and herders and engaged in their every activity. In addition, I noticed weather patterns and physical environment during my stay in Nhāson which helped me to contextualize the issue in details. 
Likewise, I again visited the area in June and October in 2018 for doing research in ethnography of school and livestock management practices in the changing context. I also observed physical environment and social life. Focused on the single community and living with them for a long period helped me to understand the social and cultural meanings of seasons.

\section{CONCEPTUAL FRAMEWORK}

Figure 1 shows the Nhāson people's categorization of seasons and embeddedness of social life according to seasons. They put year in the center and divide them into months. In the second layer, 12 months are divided into four larger segments with reference to the weather patterns snowfall, plants flowering, rainfall and dewfall and clear sky - notice in the surroundings. Each segment consists of three months which is known as sho (season). Sho are named differently. One is based on the observed weather pattern; and another is based on upwards and downwards movement of herds. Moreover, feasts and festivals, migration, herbs collection, firewood collection, weaving etc. varies according to sho. This shows the nexus between seasons and social seasonality. The separation of one from another does not make sense of seasons to the people of Nhāson.

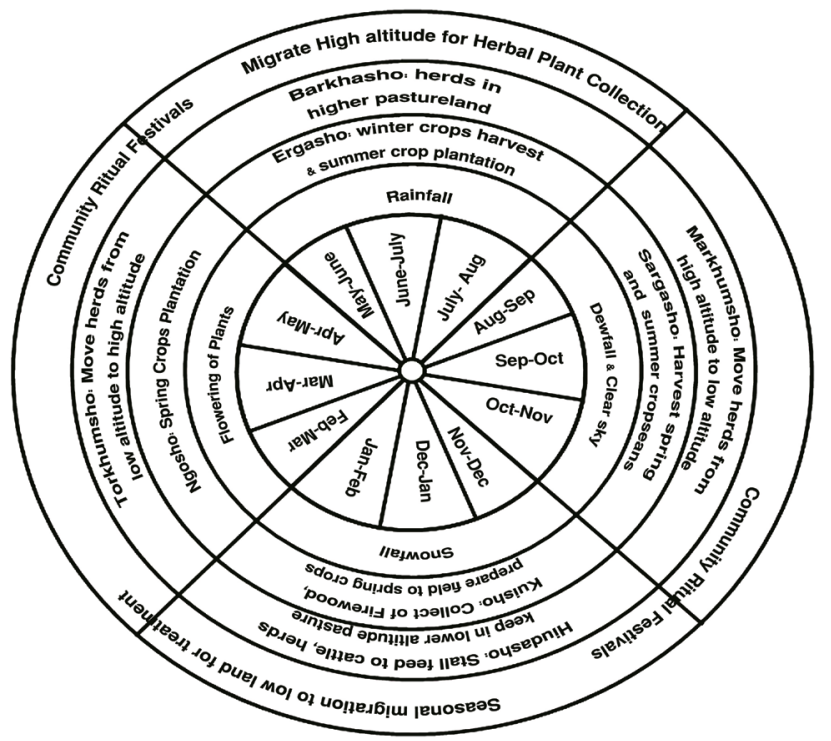

Figure 1: Seasons and social life in Nhāson

Source: Poudel 2016. 


\section{RESULTS AND DISCUSSIONS}

\section{Seasons as a social category}

When I started to talk about the seasons with the people of Nhāson, I found the naming systems of seasons are categorized entirely in different way according to their occupations. Farmers linked seasons with farming activities whereas herders to mobility of their herds. But nobody overlooks weather patterns appearance in their surroundings. Moreover, they see the seasons through nexus of physical seasonality and socio-cultural seasonality.

\section{Herders' naming systems of seasons and the social life}

The herders of Nhāson move their livestock in different pasturelands on rotational basis based on the seasons. In winter, they move their livestock downwards and in summer upwards. Based on that year is divided into two broad seasons -torkhumsho and markhumsho. The word torkhumsho is composed of Gurung's two words, torkhum and sho meaning 'upwards' and 'season'. Together, it means 'upwards season'. It begins on $1^{\text {st }}$ Magha (approximately on 16 January) and remains on $32^{\text {nd }} A$ sar (approximately on 15 July). The later word markhumsho is consisting of Gurung's two words markhum and sho. The former refers to 'downwards' and the latter to 'season'. Thus, it is a 'downwards season'. It onsets on $1{ }^{\text {st }}$ Shrawan (approximately on 16 July) and ends on $30^{\text {th }}$ Paush (approximately on 15 January).

A wider variation in weather patterns exists in torkhumsho and markhumsho. With the beginning of turkhumsho, days begin to be warmer; snow begins to melt; grasses begin to grow; wild animals and birds start to move gradually up to higher altitude and so forth. The socio-cultural life of the herders is also shaped by seasons. In turkhumsho, herders start to drive their herds to high pasturelands after a month of the beginning of the season and they reach in the highest pastureland in the end of the season. In the season, livestock spread out more widely in scattered camps in the season. Only a herder is in each camp and his family lives in the village. It reveals a break up with family for a short period. It does not mean that a herder lives a completely isolated life for the entire season. His family members frequently visit the camp with foods, drinks and tobacco.

In turkhumsho, the people of Nhāson, especially herders, exploit far distance ecological landscape where enough and nutritious grasses are available to feed the livestock. Moreover, seasons significantly affect the herd management system in Nhāson. In turkhumsho, the small herds (those who have less than 20 heads of cattle) are managed. Two or more households keep their herds together by hiring a herder. Including salary, 
each household contributes food and tobacco to the hired herder equally. It shows a strong social and economic cooperation among the small herders in turkhumsho to manage their herds.

In markhusho I noticed that weather pattern is not like turkhumsho. In the beginning of the season, days are not chilly. But after a month, days start to be chilly, reach in peak in the mid, and gradually fall down by the end. Dews start to fall in higher altitude and grasses turn brown and die out. Birds and animals gradually start to move to lower altitude. With the onset of dewfall, herders also start to move their livestock from high altitude to lower one, and finally reach at villages and their surroundings. In Nhāson valley, grazing lands are very limited at village surroundings. There are no more grasses on grazing lands. It is, therefore, very hard to manage a large herd. It requires hay and fodder. I did not see huge amount of hay for the livestock. Due to lack of enough fodder, the joint management system of herds cannot operate smoothly at all. Therefore, each household separates his/her herd and keeps it separately. Herds are not only separated, the sharing of foods and salary for hired herder no longer function. It reflects that small herders again fragment into fairly independent herd in markhumsho to manage livestock.

Form economic perspective, I noticed a wider economic transition of livestock in markhumsho which hardly observed in turkhumsho. Each herder sells about one third of their livestock especially goat and sheep in the season. The reduction of size of herds in the beginning of markhumsho by the herders in Nhason valley seems ecologically more rationale because available resources gradually go down and almost become scarce in the end of the season due to the chilly climate. Selling of livestock is more sex specific. They only sell male one, but not the female. Female livestock are required for the reproduction to the year to come. The selling of female one is to reduce the size of herd. They do not, therefore, want to take risk of reducing the size of herd by selling female one.

The people of Nhāson perform two types of rituals; i) household ritual, and ii) community/village ritual. I did not see any relation between seasons and household rituals because they are practiced or performed in any seasons as per the required of an individual household. However, community/village rituals are fixed and closely interconnected with seasons. For example, the community festivals such as aakhekutu, ramne, propropra, nakaudanda, dobate, tön, töten and so on are arranged in the beginning of torkhumsho or the end of markhumsho when herders and their herds are at the vicinity of village's settlement. Likewise, marriage ceremony is also generally arranged at the end of markhumsho. For instance, five marriage 
ceremonies were occurred at Tache in 2012 in which four held in the $2^{\text {nd }}$ half of markhumsho and one in first half of torkhumsho. At that time, most of the villagers are at home and herds are nearby the settlements. By this, all villagers can participate and contribute in rituals and festivals.

In Nhāson, I saw the participants of all the members are compulsory. Households that cannot physically present in the ritual also contribute by providing cash and kinds. In each community ritual, a feast is essential. Meat and cooked rice are the main items of food and local brew and tea are drinking items. It requires huge amount of meat to feed the participants. It is only fulfilled through either slaughtering of fatty livestock or collecting/ stocking a large number of livestock at a once. If we look the practice from adaptive perspective, the first is more rationale than the latter one. In markhumsho, livestock can get more nutrition if they get a caravan to graze on which results in their proper physical nourishment. Hence, they can acquire a large amount of meat from few numbers of livestock. Thus, such slaughtering of only few livestock in Nhāson seems economically more rationale and ecologically adaptive.

Torkhumsho and Markhumsho are not just divisions of a year for the herders, but it is something more than that. The data reveals that the socio-cultural and economic life of the herders is entirely distinct in each season which is largely shaped by the weather patterns. Social cooperation becomes strong in torkhumsho through collectively managing the herds for the exploitation of wider ecological niche and it becomes weak in markhumsho due to limited resources available to feed livestock in the season. However, economic transition and family integration are more in markhumsho than turkhumso. Moreover, community festival and seasons are also economically and ecologically interconnected in Nhāson .

\section{Farmers' naming systems of seasons and the social life}

In Nhāson valley, farmers name the seasons as kuisho, ngosho, ergasho and sargasho based on physical objects appearance on the environment. This is another way of marking the seasons. The term kuisho is made up of two Gurung two words kui (snow) and sho (season) meaning snowing season. The season starts from mid-November and ends in midFebruary. Snow begins to fall in the beginning of the season and goes up in the mid, and gradually down by the end of the season. Before starting of kuisho, farmers complete harvesting of summer crops and their residues that used as stall feeding to livestock in the winter. If they do not harvest the crops and their residues, they will lose it permanently. The season starts with the plantation of winter crops like wheat, naked barley and potato on the farmland and then other agricultural activities are completely absent in 
the village due to heavy and on and on snowfall. Villagers are almost free due to harvesting of summer crops and sowing of winter crops. Such free time is utilized by women as weaving woolen blankets and mats. Young generation starts learning weaving from their mothers and elder relatives. This reveals that knowledge and skill of weaving transform from old generation to young one on the one hand, and, on the other it makes closer to young generation and the old one. However, weaving of woolen blanket and mats is gradually fading out in the village along with the arrival of ready-made carpet and blanket. The displacement of weaving blanket and mat has wider impacts on indigenous knowledge, culture and social fabric. Weaving as indigenous knowledge and skill, of Gurung culture and social fabric has been getting weaker as ready-made blanket and carpet available.

I saw the mobility of Nhāson people and seasons are also closely embedded to each other. As compare to other seasons, temporary downward mobility of people is higher in kuisho. It is due to cold climate and more leisure. All people, however, do not leave the village. Only the members of rich families leave the village and go to Lamjung, Pokhara and Kathmandu to protect them from cold. They utilize the time for medical check-up. In addition, they also visit to kin. It does not mean that they do not visit kin in other season. They do it, but the frequency is higher in this season than others. It reflects the optimum utilization of free time by the people of Nhāson valley. They cannot do anything outside household activities like farming during the season due to harsh cold weather. Such harsh cold weather is used for other purposes like medical check-up and strengthened kinship ties with kin who live far from the village.

The period from mid-February to mid-May is called ngosho. In Gurung language, ngo means flowering of plant and sho means season. Therefore, ngosho means plants flowering season. It is also called khalokhalli-ngije, meaning flowering of peach and walnut. Snows become rare, and days become warmer. Naked-barley and wheat that planted in kuisho begin to grow rapidly. Snow starts to melt in highland and new plants start to germinate in meadows. Rhododendron, apple, walnut and peach and other flowering plants begin to blossom.

In the season, farmers back to farm again. In the first quarter of the season, they prepare the field for potato, maize, beans and soybean and plant them in the mid-season, and weed them at the end of the season. The villagers told me that the season is dry. No or very rare rainfall occurs during the season. Water in the springs, rivulets and rivers decrease in volume and sometimes springs may dry up. But in the mid-season, usually, 
not always, stormy rain may suddenly fall that destroy baby fruits of peach, walnut, apple and plum.

I noticed that most of the community rituals like tön, ankhekutu, propropra, nakaudanda, töten, dobate, ramne, yankhuba, rheepaba are perform during the ngosho. These rituals are organized for the prosperity of village and villagers and good crops and livestock. If either deities will not happy with them or bad spirits live in the village, they cannot grow good crops. Therefore, it is essential to drive off the bad spirits or evil eyes of the village or household for better productivity on the one hand, and, on the other to make their deities happy. The farmers of Nhāson perform household or community rituals before planting the crops for good productivity. They also perform the rituals after harvesting the crops with aim of giving thanks to deities. For the farmers of Nhāson deities' hands is up for good productivity. Therefore, performing the community rituals are like 'the thanks giving rituals'. They respect 'the givers'. Without performing the ritual they do not consume foods.

The $3^{\text {rd }}$ season is ergasho means rainy season. It starts from midJune and ends in mid-August. Sky is mostly covered with clouds; drizzle rains occur; and trails and roads become muddy. In the season, springs, rivulets and rivers rise again due to rains. The first harvesting of crops in the year starts. I noticed that farmers are engaged in harvesting winter crops like wheat, naked barely and potato in the early phase of the season and planting of summer crops (buckwheat, summer maize, naked barley and wheat) and weeding of summer maize in the mid of the season, and harvesting of spring crops (beans, potato and maize) in the end (crops harvesting times have been shorted 15 to 30 days in the valley due to global warming). The villagers do not perform any community ritual in the season, although household ritual like polebaliba (removing the bad spirits) can be organized by a household for household's prosperity.

After the end of the ergasho, the sky is appeared as cloudless and ground is covered with dewfall in the morning. This is called sargasho. In Gurung language sargasho means the 'clear-sky-season'. Rain does not completely stop at the first quarter of the season, and sky is not clear. The villagers reported that rainfall goes continue for the first 15 days of sargasho. As Vedwan (2001) said, this indicates a transitional phase between two seasons which is typically over-determined and marked by the presence of several independent but related indicators i.e., rain and cloudy sky.

It was informed me that grasses turn brown in pasture land due to dewfalls and herds start to move towards the lower altitude (I have already discussed). In the beginning of the season, buckwheat starts flowering; 
summer naked barley and wheat start to grow; and spring crops like maize and potato begin to ripe. Therefore, buckwheat, naked barley, wheat and maize terraces begin to look pink, green or yellow. The season is an end of the agricultural activity. Nashon people harvest all crops planted in spring seasons or summer seasons. In the end of the season, they also prepare field for winter crops in some patches of land. Two Hindu festivals like Dashain and Tihar are performed that they adapted from Hindu community. At the end of season, villagers again arrange some community rituals like ankhekutu, proprapro, nakaudanda, töten etc. for giving thanks to their deities for giving them good productivity.

The data presented that social life of Nhāson people is constructed differently in different seasons. In kuisho, farmers are free but use it for knowledge transformation and visiting to kin and city for medical checkup. However, in other seasons they are busy in farming activities. Moreover, community rituals are only arranged in two seasons like ngosho and sargasho. It means village cooperation is higher in ngosho and sargasho than kuisho and ergasho.

\section{CONCLUSION}

The data presented in the text challenges state defined universal definition of seasons that based on a single framework for marking and counting a year such as basanta (spring), grishma (pre-monsoon), barsha (rainy), sharad (autumn), hemanta (pre-winter) and shisir (winter) in Nepal and India and spring, summer, autumn/fall and winter in Europe and the USA. The naming systems of seasons among the highlanders in Nepal again force us to rethink on universal marking and defining systems of environment including the seasons. Locals' definitions of seasons are cultural specific and place-specific. As a cultural specific, a single community having different culture and cultural practices has multiple frameworks for defining seasons.

The data presented in the text confronts with the western ideas that treat nature and culture as separate entity (Ingold 2000). Seasons cannot be accounted for exclusively technological sense (Mauss 1977). Seasons are integrated and embedded with culture and social life of highlanders. The social life of highlanders does not continue at the same level throughout a year; it goes regular, successive phases of up and down of activity and social integration and cooperation. It goes side by side as rhythms. The change of seasons from one season to another is, therefore, not just a matter of change in weather patterns and the associated changes in physical environment of the surroundings; but it is a change in social life. 
Understanding of ethno-seasonality provides us a holistic picture of community which is based on integrated modeling approach i.e., linking social and ecological systems. The approach does not treat social and environmental domains as topics for separate. The separation of environmental system from social system and vice versa, we cannot fully account complexity of human relations with natural world including the interconnectedness between seasons and social life.

\section{REFERENCES}

Basso, K. (1996). Wisdom sit in places: Landscape and language among the Western Apache. Albuquerque: University of New Mexico Press.

Bauer, K.M. (2004). High frontiers: Dolpo and the changing world of Himalayan pastoralists. New York: Colombia University Press.

Berkes, F. (2008). Sacred ecology. London \& New York: Routledge

Evans-Pritchard, E.E. (1940). The Nuer: A description of the modes of livelihood and political institutions of a Nilotic people. New York and Oxford: Oxford University Press.

Harris, M. (1998). The rhythm of life on the Amazon floodplain: Seasonality and sociality in a riverine village. Journal of Royal Anthropological Institute, 4(1): 65-85.

(HMGN). (2000). Topo-maps of Nepal: Sheet No. 2884-06 \& 2884-10. Department of Survey, His Majesty of Government of Nepal, Kathmandu, Nepal.

Ingold, T. (2000). Perception of the environment: Essays in livelihood, dwelling and skill. London: Routledge

Ingold, T. \& Kurttila, T. (2000). Perceiving the environment in Finnish Lapland. Body and Society 6(3-4):183-196.

Kruse, F. (2013). Seasons as rhythms on the Kemi River in Finnish Lapland. Ethnos: Journal of Anthropology, 78(1): 23-46.

March, K. S. (1983). Weaving, writing and gender. Man 18(4): 729-744.

Mauss, M. (1979). Seasonal variations of the Eskimo: A study in social morphology. London, Boston \& Henley: Routledge \& Kegan Paul.

Molnar, A. (1981). Economic strategies and ecological constraints: case of the Kham Magar of north west Nepal. In Christoph von FürerHamindrof (Ed.) Asian highland societies: In anthropological perspectives. (pp. 20-51). New Delhi: Sterling Publishers. 
Orlove, B. (2003). How people name season. In S. Strauss and B. Orlove, (eds.) Weather, climate and culture. Oxford: Berg. pp. 212-240.

Poudel, J.M. (2018a). Anthropology of landslide: An emic perspective from Nhāson. In L. P. Uprety, B. Pokharel, J. Rai, S. Dhakal \& M. S. Lama (eds.). Contemporary Nepali society and cultural anthropology: A reader. Kathmandu: Central Department of Anthropology. pp. 130150.

Poudel, J. M. (2018b). Pond becomes a lake: Challenges posed by climate change in the Trans-Himalaya regions of Nepal. Journal of Forest and Livelihood 16(1): 87-102

Poudel, J.M. (2016a). Climate change, farming and livestock: A study on perceptions, knowledge and responses among the people of Nhāson, Manang. A PhD Thesis, Tribhuvan University.

Poudel, J. M. (2016b). Delineating territory: Local narratives and practices. In B. Pokharel, J. Rai, \& M. S. L. Tamang (Eds.) Nepali anthropology: New direction and contributions. Kathmandu: Central Department Anthropology, Tribhuvan University. pp.183204.

Rappaport, R. A. (1979). Ecology, meaning and religion. Berkeley, CA: North Atlantic Books.

Van-Spengen, W. (2010). Tibetan broader worlds: A geo-historical analysis of trade and traders. London and New York: Routledge.

Spoon, J. (2011). The heterogeneity of Khumbu Sherpa ecological knowledge and understanding in Sagarmatha (Mount Everest) national park and buffer zone, Nepal. Human Ecology 39(5): 657672.

Von-Fürer-Haimendrof, C. (1980). A Himalayan tribe: From cattle to cash. Berkeley: University of California Press.

Vedwan, N. (2006). Culture, climate and the environment: Local knowledge and perception of climate change among apple growers in northwestern India. Journal of Ecological Anthropology 10: 4-18. 